\title{
Analysis of Voltage Source Inverters using Space Vector PWM for Induction Motor Drive
}

\author{
Preeti Soni ${ }^{1}$, Kavita Burse ${ }^{2}$ \\ ${ }^{1}$ Department of Electrical and Electronics Engineering, Oriental College of Technology, \\ Bhopal, Madhya Pradesh, India
}

\begin{abstract}
The Adjustable Speed Drives (ADS) are generally used in industry. In most drives AC motors are applied. The standard drives used are Induction Motors (IM) and recently Permanent Magnet Synchronous Motors (PMSM) are also used. Developments in power electronics and semiconductor technology have lead to improvements in power electronic systems. Different circuit configurations namely multilevel inverters have become popular and considerable research interest is generated in them. Variable voltage and frequency supply to $A C$ drives is invariably obtained from a three-phase voltage source inverter. A number of Pulse width modulation (PWM) schemes are used to obtain variable voltage and frequency supply. The most widely used $P W M$ schemes for three-phase voltage source inverters are carrier-based sinusoidal PWM and space vector $P W M(S V P W M)$. There is an increasing trend of using SVPWM because of their easier digital realization and better DC bus utilization. This paper proposes SVPWM implementation of an Induction motor. The model of a three-phase voltage source inverter is discussed based on space vector theory. Simulation results are obtained using MATLAB/Simulink environment.
\end{abstract}

Keywords: Induction motor drive, MATLAB, Simulation. Space vector PWM; Voltage source inverter drive.

\section{INTRODUCTION}

The voltage source inverters (VSI) fed variable speed AC drives have gained more importance in many industrial applications. To get variable voltage, variable frequency supplies from a VSI, the PWM algorithms are becoming more popular due to their advantages. A detailed survey of various PWM algorithms is given in [1]. Three-level voltage-fed PWM inverters are recently gaining popularity for multi-megawatt industrial drive applications [2]. In recent years, the space vector PWM (SVPWM) algorithm is attracting many researchers. The SVPWM method is an advanced, computation-intensive PWM method and possibly the best among all the PWM techniques for variable frequency drive application $[2,3]$. This technique results in higher magnitude of fundamental output voltage available as compared to sinusoidal PWM. However, SVPWM algorithm used in three-level inverters is more complex because of large number of inverter switching states. Space vector approach has the advantages of lower current harmonics and a possible higher modulation index compared with the three phase sinusoidal modulation method and ease of digital implementation [4]. The SVPWM method considers interaction of the phase and optimizes the harmonic content of the three phase isolated neutral load as shown in Fig. 1.

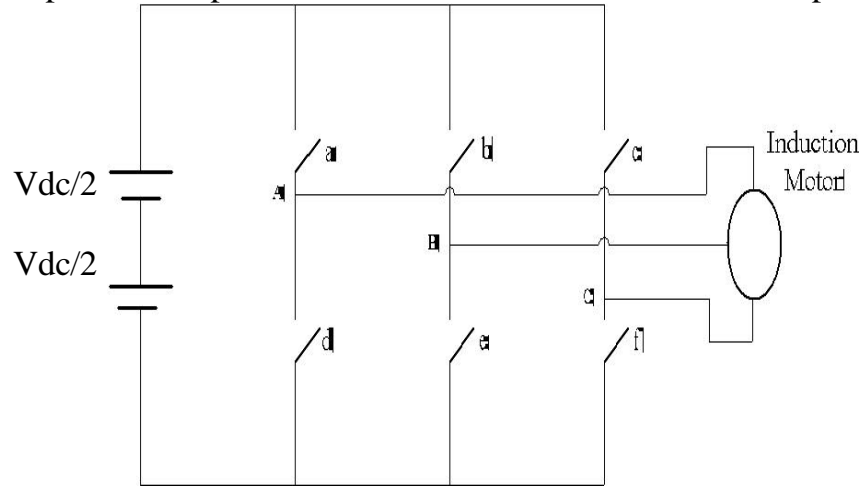

Fig, 1 Voltage source inverter type 3 phase

This paper presents modeling and simulation of SVPWM algorithms for VSI fed induction motor drives. Finally, the computer simulations using Simulink/ MATLAB package program confirm the capabilities of the new technique 


\section{THREE PHASE INVERTER}

The structure of a typical 3-phase power inverter is shown in Fig. 2, where $\mathrm{V}_{\mathrm{A}}, \mathrm{V}_{\mathrm{B}}, \mathrm{V}_{\mathrm{C}}$ are the voltages applied to the star-connected motor windings, and where $\mathrm{V}_{\mathrm{DC}}$ is the continuous inverter input voltage

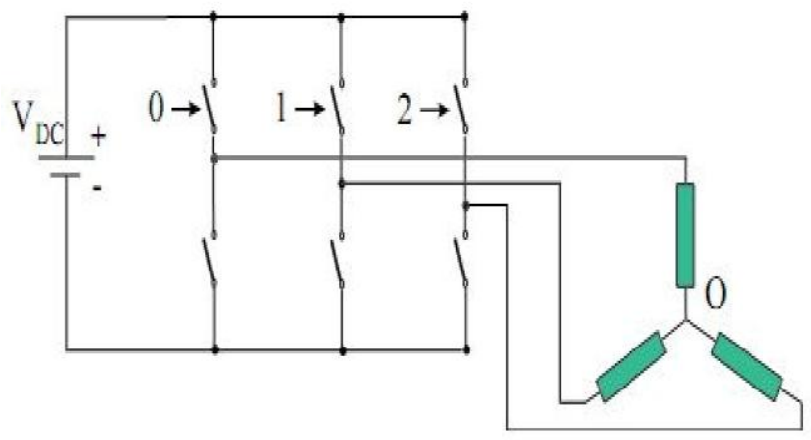

Fig. 2 Basic scheme of 3-phase inverter and AC-motor

The six switches can be power BJT, GTO, IGBT etc. The ON-OFF sequence of all these devices must satisfy the following conditions:

- Three of the switches must always be ON and three always OFF.

- The upper and the lower switches of the same leg are driven with two complementary pulsed signals. In this way no vertical conduction is possible, provided care is taken to ensure that there is no overlap in the power switch transitions.

\section{Space Vector Pulse Width Modulation for 3-Phase VSI}

The ac output voltage produced by the VSI of a standard ASD is a three-level waveform. Although this waveform is not sinusoidal as expected its fundamental component behaves as such. This behavior should be ensured by a modulating technique that controls the amount of time and the sequence used to switch the power valves on and off. The modulating techniques most used are the carrier-based technique (e.g., sinusoidal pulse width modulation, SPWM), the space-vector (SV) technique, and the selective-harmonic-elimination (SHE) technique. Three-leg voltage source inverter is because of the constraint that the input lines must never be shorted and the output current must always be continuous a voltage source inverter can assume only eight distinct topologies. Six out of the eight topologies produce a nonzero output voltage and are known as non-zero switching states and the remaining two topologies produce zero output voltage and are known as zero switching states [5].

Space vector modulation (SVM) for three-leg VSI is based on the representation of the three phase quantities as vectors in a two-dimensional plane in Fig. 3. We see that the line voltages $\boldsymbol{V a b}, \boldsymbol{V} \boldsymbol{b} \boldsymbol{c}$, and $\boldsymbol{V} \boldsymbol{c a}$ are given by

$$
\begin{aligned}
& V_{a b}=V_{g} \\
& V_{b c}=\mathrm{O} \\
& V_{c a}=-V_{g}
\end{aligned}
$$

This can be represented in the $\alpha, \beta$ plane as shown in Figure 4, where voltages Vab, Vbc, and Vca are three line voltage vectors displaced by 120 in space [6]. The effective voltage vector generated by this topology is represented as V1(pnn) in Figure 4. Here the notation 'pnn' refers to the three legs/phases a, b, c being either connected to the positive dc rail (p) or to the negative dc rail (n). Thus 'pnn' corresponds to 'phase a' being connected to the positive dc rail and phase $\mathrm{b}$ and $\mathrm{c}$ being connected to the negative dc rail.

Space Vector PWM supplies the AC machine with the desired phase voltages. The SVPWM method of generating the pulsed signals fits the above requirements and minimizes the harmonic contents. Note that the harmonic contents determine the copper losses of the machine which account for a major portion of the machine losses. Taking into consideration the two constraints quoted above there are eight possible combinations for the switch commands. These eight switch combinations determine eight phase voltage configurations. The vectors divide the plan into six sectors. Depending on the sector that the voltage reference is in, two adjacent vectors are chosen.

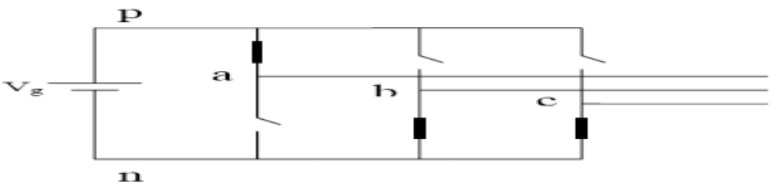

Fig. 3: Topology 1-V1 (pnn) of a voltage source inverter 


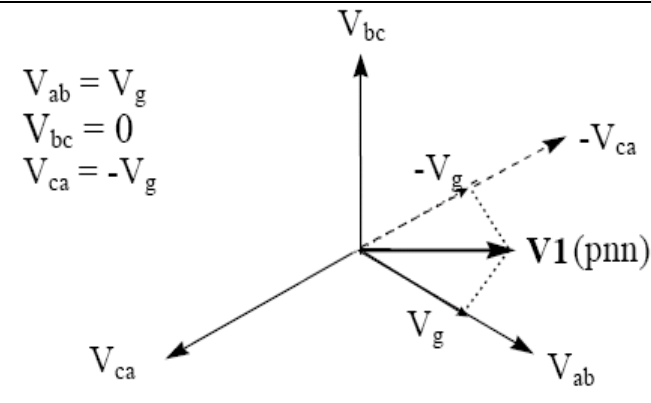

Fig. 4: Representation of topology 1 in the $\alpha, \beta$ plane

Proceeding on similar lines the six non-zero voltage vectors (V1 - V6) can be shown to assume the positions shown in Fig.5. The tips of these vectors form a regular hexagon. We define the area enclosed by two adjacent vectors, within the hexagon, as a sector. Thus there are six sectors numbered $1-6$ in Fig. 5

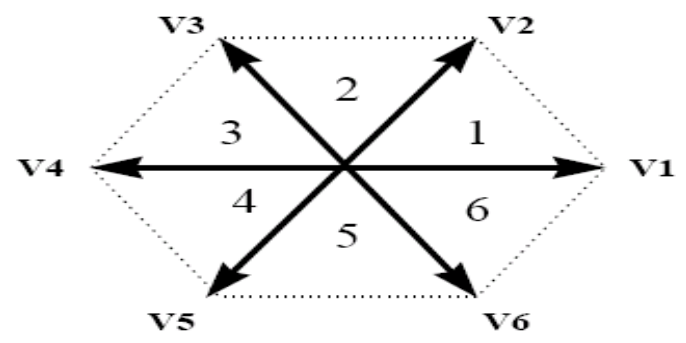

Fig. 5 Non-zero voltage vectors in the $\alpha, \beta$ plane.

\section{iv COMPARISON Of SinUSOIDAl AND SPACE Vector PWM}

The SVPWM generates minimum harmonic distortion of the currents in the winding of 3-phase AC motor. SV Modulation also provides a more efficient use of the supply voltage in comparison with sinusoidal modulation methods. In fact, with conventional sinusoidal modulation [1],[7],[8] in which the sinusoidal signals are compared with a triangular carrier, we know that the locus of the reference vector is the inside of a circle with a radius of $1 / 2 \mathrm{~V}_{\mathrm{DC}}$. In the $\mathrm{SV}$ modulation it can be shown that the length of each of the six vectors is $2 / 3$ $\mathrm{V}_{\mathrm{DC}}$. In steady state the reference vector magnitude might be constant. This fact makes the SV modulation reference vector locus smaller than the hexagon described above. This locus narrows itself to the circle inscribed within the hexagon, thus having a radius of $1 / 3 \mathrm{~V}_{\mathrm{DC}}$. In Fig. 6 below the different reference vector loci are presented.

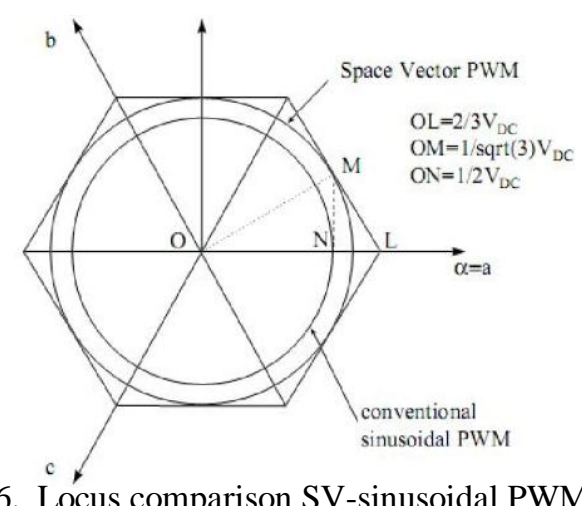

Therefore, the maximum output voltage based on the Space Vector theory is $1.15 \mathrm{OM} / \mathrm{ON}$ times as large as that of the conventional sinusoidal modulation. This explains why, with SVPWM, we have a more efficient use of the supply voltage than with the sinusoidal PWM method. Machine equations are converted in the rotor flux frame. Rotor flux is turning in synchronous speed but in a different angle than stator flux, if there is a sinusoidal excitation. Choosing d-axis on the rotor flux, $\mathrm{q}$ component will be zero.

This fact simplifies the equations very much. This method is very similar to DC machine's independent excitation where flux is the function of field current and torque is in proportion with flux and rotor current. The main problem of vector control method is flux axis angle calculation where is done by measuring the flux in two points with 90 degrees displacement and then angles are calculated using the resulted fluxes or estimating in regard to rotor speed [9]. 


\section{Matlab Simulation Of An Im Using Svpwm Technique}

This circuit uses the AC2 block of SimPowerSystems library. It models a PWM VSI induction motor drive with a braking chopper for a 3HP AC motor shown in figure 7.The induction motor is fed by a PWM inverter, which is built using a Universal Bridge Block. The speed controller consists in a PI regulator that produces a slip compensation, which is added to the rotor speed in order to derive the commanded stator voltage frequency.[10] A constant volts per hertz ratio is also applied to the motor. The motor drives a mechanical load characterized by inertia J, friction coefficient B, and load torque TL. Motor current, speed, and torque signals are available at the output of the block. Start the simulation. You can observe the motor stator current, the rotor speed, the electromagnetic torque and the DC bus voltage on the scope. The speed set point and the torque set point are also shown.
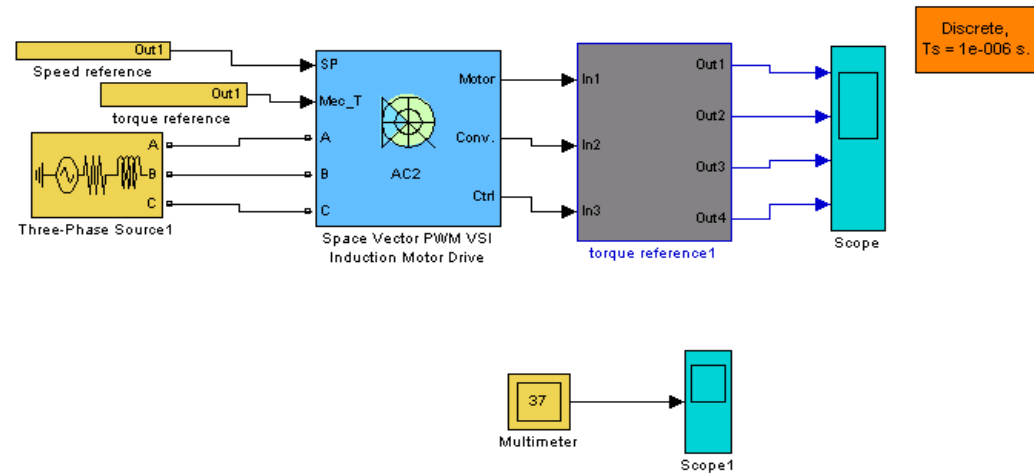

Fig. 7 Simulation in MATLAB

\section{Simulation AND RESUlT}

Start the simulation. Observe the stator current, DC bus voltage electromagnetic torque, and rotor speed during the starting on the scope. At the end of the simulation time $(3 \mathrm{~s})$, the system has reached its steady-state. Response to a change in reference speed and load torque is discussed:

At time $\mathrm{t}=0 \mathrm{~s}$, the speed set point is $1000 \mathrm{rpm}$. As shown in Figure 8, the speed follows precisely the acceleration ramp.

At $t=0.5 \mathrm{~s}$, the full load torque is applied to the motor shaft while the motor speed is still ramping to its final value. This forces the electromagnetic torque to increase to a high value and then to stabilize at $11 \mathrm{~N} . \mathrm{m}$ once the speed ramping is completed and the motor has reached $1000 \mathrm{rpm}$.

At $\mathrm{t}=1 \mathrm{~s}$, the speed set point is changed to $1500 \mathrm{rpm}$ and the electromagnetic torque reaches again a high value so that the speed ramps precisely at $1800 \mathrm{rpm} / \mathrm{s}$ up to $1500 \mathrm{rpm}$ under full load.

At $\mathrm{t}=1.5 \mathrm{~s}$, the mechanical load passed from $11 \mathrm{~N} . \mathrm{m}$ to $-11 \mathrm{~N} . \mathrm{m}$, which causes the electromagnetic torque to stabilize at approximately at -11 N.m shortly after.

The DC bus voltage increases since the motor is in the braking mode. This increase is limited by the action of the braking chopper. 1) The power system has been discretised with a 1 us time step. The speed controller uses a 100 us sample time and the space vector modulator uses a 20 us sample time in order to simulate a microcontroller control device as shown in figure 9 and in figure 10.

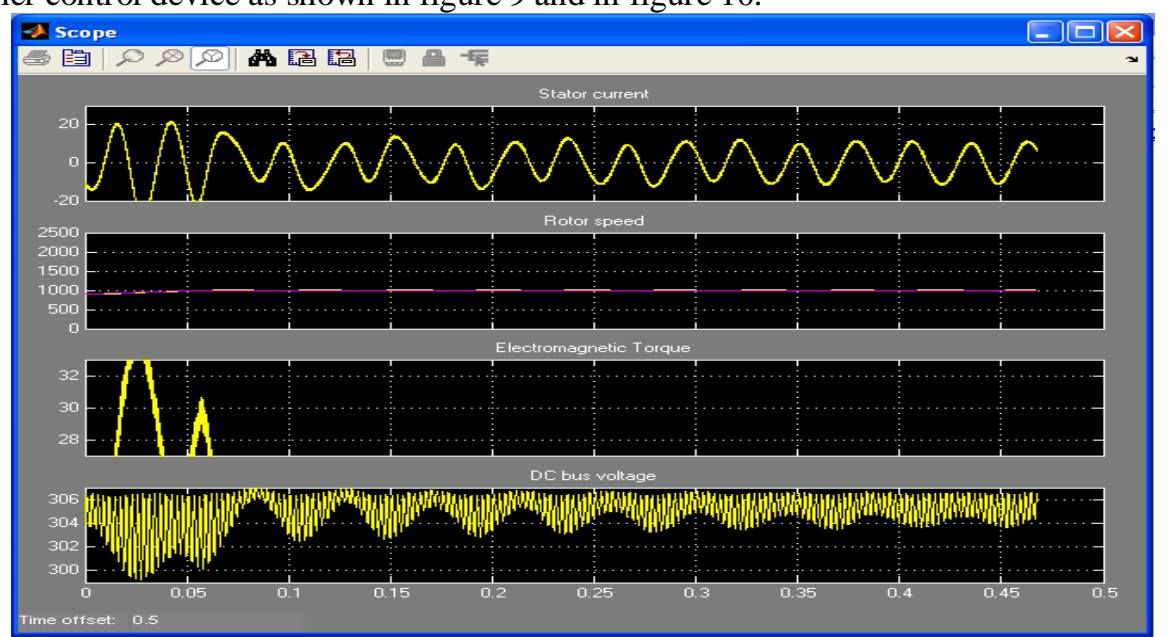

Fig. 8: Response of stator current, rotor speed torque and DC bus voltage versus time 


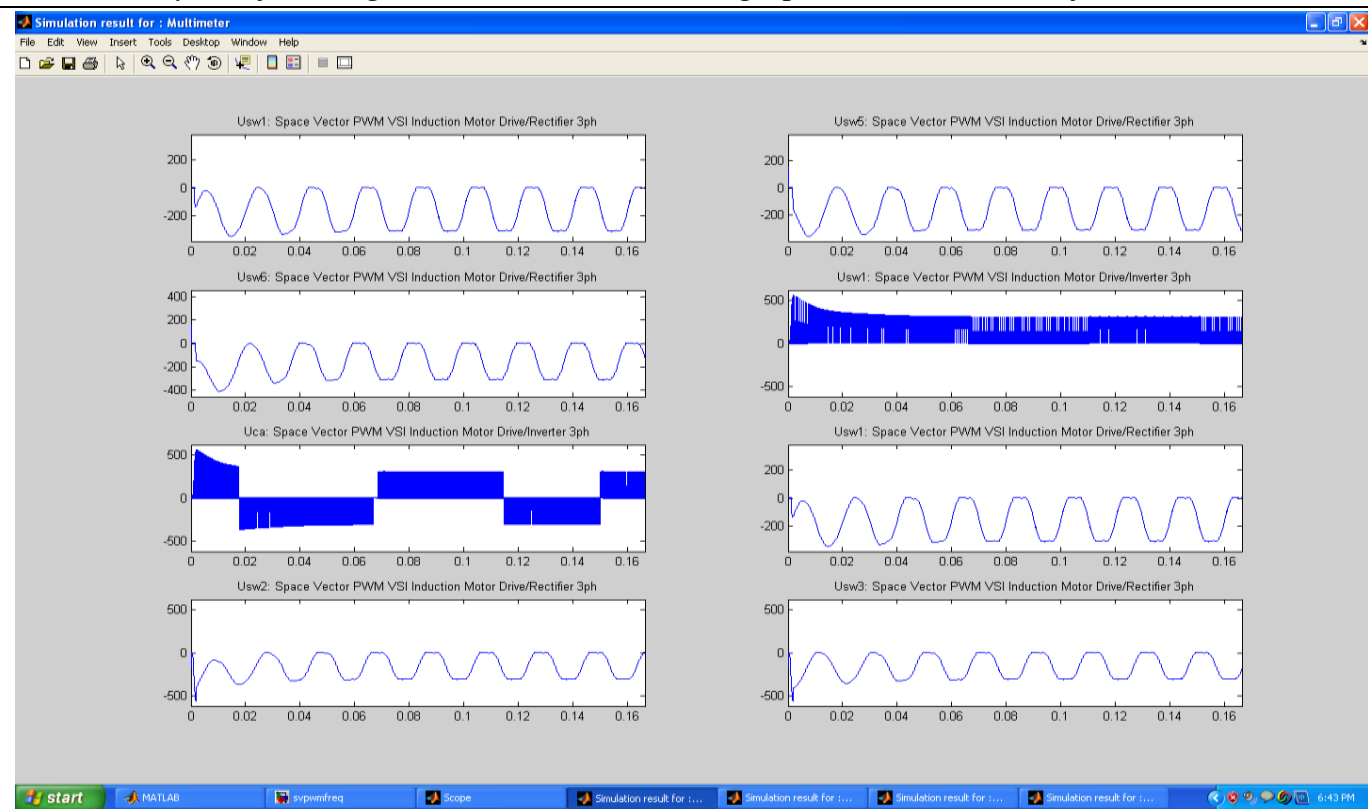

Fig. 9: Response of six sector voltage(Usw1 - Usw6) versus time

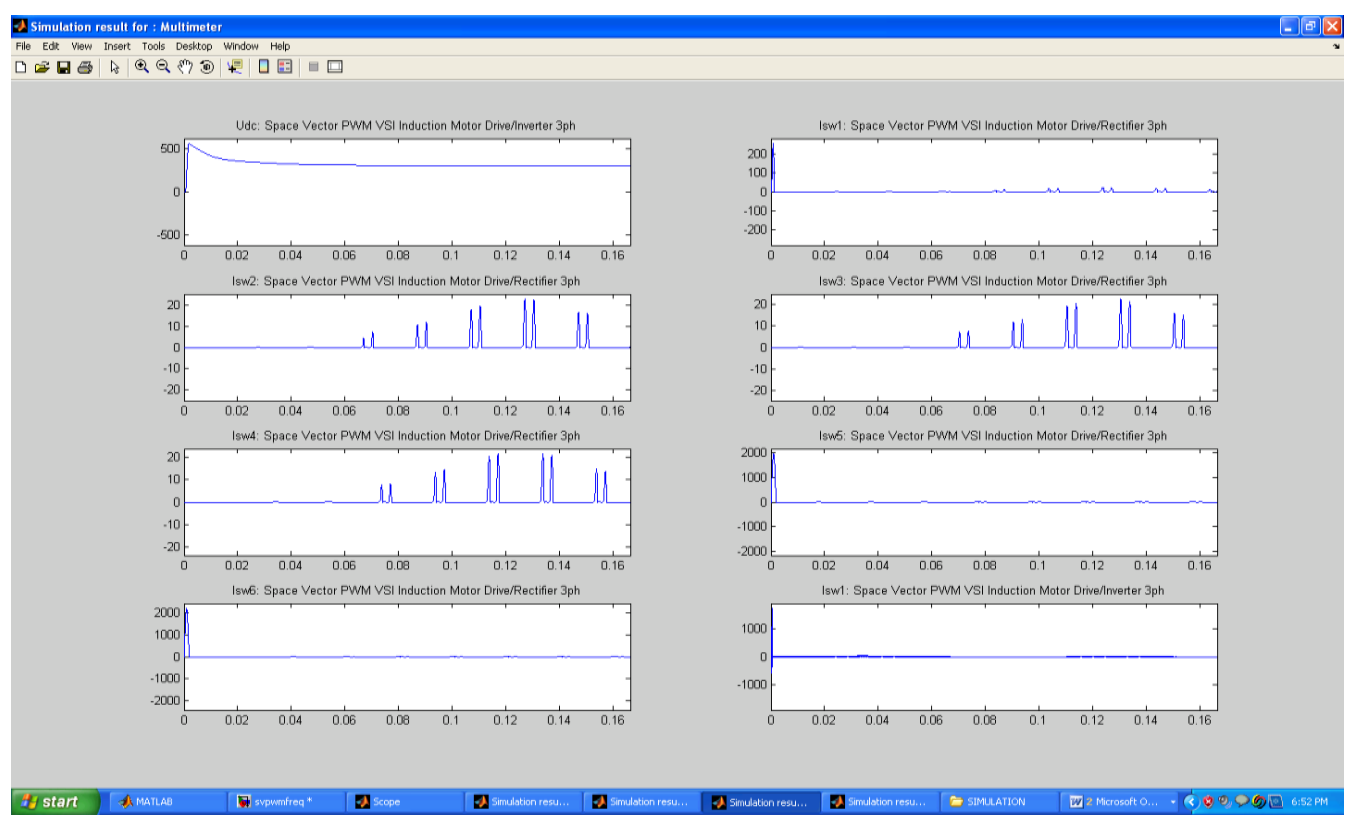

Fig. 10: Response of DC bus voltage and six sector current(Isw1 - Isw6) versus time

VII. Latest Improvements by using these techniques

There is an increasing trend of using space vector PWM (SVPWM) because of their easier digital realization and better dc bus utilization. An adjustable speed drive (ASD) is a device used to provide continuous range process speed control (as compared to discrete speed control as in gearboxes or multi-speed motors). An ASD is capable of adjusting both speed and torque from an induction or synchronous motor. Space Vector PWM is superior as compared to Sinusoidal pulse width modulation in many aspects like:

- The Modulation Index is higher for SVPWM as compared to SPWM.

- The output voltage is about $15 \%$ more in case of SVPWM as compared to SPWM.

- The current and torque harmonics produced are much less in case of SVPWM

- Microprocessor-based controllers eliminate analog, potentiometer-based adjustments.

- Digital control capability.

- Built-in Power Factor correction.

- Radio Frequency Interference (RFI) filters.

- Short Circuit Protection (automatic shutdown). 
- Advanced circuitry to detect motor rotor position by sampling power at terminals, ASD and motor circuitry combined to keep power waveforms sinusoidal, minimizing power losses. Motor Control Centers (MCC) coupled with the ASD using real-time monitors to trace motor-drive system performance.

- Higher starting torques at low speeds (up to $150 \%$ running torque) up to $500 \mathrm{HP}$, in voltage source drives.

\section{Conclusion}

A simple generalized Matlab/Simulink model is presented to implement SVPWM for a three phase VSI. In this work, a three-level inverter using space vector modulation strategy has been modeled and simulated. Through the simulations, it is confirmed that the proposed SVPWM technique, has good drive response to successive changes in speed reference and load torque. The results obtained by simulation show the feasibility of the proposed strategy. However despite all the above mentioned advantages that SVPWM enjoys over SPWM, SVPWM algorithm used in three-level inverters is more complex because of large number of inverter switching states.

\section{References}

[1] . Holtz J, Dec 1992. "Pulsewidth modulation - A survey", IEEE Trans. Ind. Electron, 39(5):410-420.

[2] ]. Mondal S.K, B.K. Bose, V. Oleschuk and J.O.P, March 2003. "Three-Level Inverter Extending Operation Into Overmodulation Region”, IEEE Trans. on Power Electronics, 18(2): 604-611.

[3] Iqbal A, September 2008. "Analysis of space vector pulse width modulation for a five phase voltage source inverter".

[4] Willi H, V. Broeck, H. Skudelny and G. Stanke, Jan/Feb 1988. "Analysis and realization of a pulsewidth modulator based on voltage space vectors", IEEE Trans. Ind. Applicat, 24(1): 142-150.

[5] J. Holtz, "Pulse width modulation for electronic power conversion," Proc. IEEE, vol. 82, pp. 1194-1214, Aug. 1994

[6] O. Ogasawara, H. Akagi, and A. Nabel, "A novel PWM scheme of voltage source inverters based on space vector theory," in Proc. EPE European Conf. Power Electronics and Applications, 1989, pp. 1197-1202.

[7] Ogasawara S, H. Akagi, A. Nabae, 1989. "A novel PWM scheme of Voltage Source Inverters based on Space Vector Theory", 74(1): 33-41.

[8] Pollmann A.J, July/August 1986. "Software Pulse width Modulation for $\mu$ P Control of AC Drives", IEEE 1986 Transactions on industry applications, 22(4): 691-696.

[9] ]. Ong C. M, 1997. "Dynamic Simulation of Electric Machinery, Using MATLAB and SIMULINK", Upper Saddle River, NJ: Prentice-Hall.

[10] www.mathworks.com 